\title{
SUBLIMINAL MESSAGES - MOTIVATING LEARNERS USING VISUAL CUES: AN EXPERIMENTAL STUDY
}

\author{
Suzana DZAMTOSKA ZDRAVKOVSKA
}

Associate Professor, Mass Communication, American University of Ras Al Khaimah

E-mail: suzana.zdravkovska@aurak.ac.ae

\section{Sabir HAQUE}

\author{
Assistant Professor, Mass Communication, \\ American University of Ras Al Khaimah \\ E-mail: sabir.haque@aurak.ac.ae
}

\section{Wiktoria SZYDLAK}

Student, Bachelor Program in Mass Communication, American University of Ras Al Khaimah

E-mail: wiktoria.szydlak@aurak.ac.ae

\begin{abstract}
Subliminal messages have grown into a contentious practice getting a bad reputation in coercive advertising and progressed towards psycholinguistic communication threads over the years. The current studies investigate how priming techniques using visual cues can change learning and motivate learners. In two phases of the experimental study, the visual system of subliminal messages was exposed to three age groups: children, teens, and adults. Results on both phases show an improvement in memory reception among the children's group. These results corroborate the effectiveness of subliminal stimulus on human beings' minds and decision-making. The subliminal message can be used as a medium for memory improvements empowering learners to reach their goals in education. Future research projects should explore well-defined aural and visual tools used for teaching and measure the effectiveness of such powerful tools.
\end{abstract}

Keywords: Subliminal messages, motivate, learners, experiment, mass media, education 


\section{INTRODUCTION}

The word subliminal comes from the Latin words sub (under) and limen (threshold), literally "below the threshold," in this case meaning below the threshold of conscious awareness (Dictionary.com). According to the Oxford Advanced Learner's Dictionary, the meaning of the word subliminal is related to something that affects your mind even though you are not aware of it (OxfordLearnersDictionaries.com). Other definitions of subliminal clarify that this term refers to something that is not recognized or understood by the conscious mind, but still has an impact on it (Cambridge English Dictionary). The explanation of the meaning of this word is even more detailed on the website of Vocabulary.com, where the subliminal (synonyms - imperceptible, unperceivable) is defined as something impossible or difficult to perceive by the mind or senses. To clarify this notion to the younger generation, there is an explanation that while our five senses are constantly sending new information to our brain, there is another way our brain receives information - through subliminal messages related to the unconscious mind that picks up on things we don't even realize (Vocabulary.com).

The introduction of subliminal messages in the media has witnessed a controversial reception. While for some, subliminal messages help businesses market their product intelligently by 'forcing' consumers into accepting a product (BBC News, 2015), for others, 'coercing' consumers to purchase items they may otherwise not need or are not necessarily good for them, is an infringement to the consumers' right of free choice (Sofi \& Nika, 2013, 17). Subliminal messages have been the subject of intense discussion since it appeared for the first time in 1957 during the subliminal advertising of CocaCola and popcorn by James Vicary in New Jersey (BBC News, 2015). The record showed that the subliminal impulses, caused by images or sounds cannot be noticed by the conscious mind. Nevertheless, they strongly influence people's consumption without them realizing it. The ability to manipulate the human mind made product distributors as well as marketing and advertising specialists fascinated. Surprisingly, even though Vicary's study was later discredited, the subliminal stimuli in media started being extensively used around the world promising great effects on potential receivers and fast sales of products (BBC News, 2015). However, the subliminal messages in media came under intense scrutiny in the 1970s from both the public and specialists which encouraged many countries to ban the use of subliminal stimuli. Despite the enactment of an international law banning the use of subliminal techniques to market products, in 1957, the biggest corporations have continued to do so (Elgendi et al, 2018).

Based on theories related to psychoanalysis and neurolinguistics (Tripathi, 2012, cited in Sandoval et al, 2018), advertising has used various types of symbology. According to Broiles (2006) and Karremans et al. (2006), the most frequently used type is sexual, referring to phallic or pelvic symbols in addition to the use of sexually attractive images inserted indiscernibly in visual, theatrical and textual material, and consciously in print material 
(Broyles, 2006; Karremans et al., 2006, cited in Sandoval et al, 2018). The theories related to psychoanalysis and neurolinguistics suggest that this type of persuasion (known as subliminal) can influence the creation of and/or a change in beliefs, attitudes and behavior, particularly in adolescents (Gross \& Hardin, 2007, cited in Sandoval et al, 2018). There are few studies on subliminal messages and their effects, in particular among young people in generation ' $Z$ ' (Sandoval et al, 2018). In addition, there is considerable evidence on the indiscriminate use of subliminal messages in films, music, audio, visual and print advertising material with the aim of changing consumption decisions, despite the lack of empirical studies validating the intent of manipulation with commercial purposes and the real effect of the subliminal impact on behaviour (Broyles, 2006; Dijksterhuis et al., 2012; Smarandescu \& Shimp, 2015, Sandoval et al, 2018).

Interestingly enough, the practice of subliminal messages can also bring about positive results. In this case, advertising is not the key point, but a self-help medium like an auditory system of subliminal messages to help learners reach their goals (Karam, 2017, p. 266). As a matter of fact, there is a high possibility of getting positive results once a medium is used by students to stimulate their interest in education and improve their learning outcome. There are so many fields including, but not limited to, memorizing, public speaking, and self-esteem that can be developed by displaying subliminal messages to the audience. Perhaps, one of the areas in which the use of subliminal messages remain under-investigated is education. In fact, many students around the world fail to achieve their goals because they have learning difficulties. In this situation, it is not fully known whether the use of subliminal messages can be helpful and if so, to what extent it can do so.

In order to address these questions, in this paper we explain how the brain structures react to subliminal stimuli; we report on and discuss psycholinguistic evidence that shows how the priming technique changes people behaviour just like subliminal messages in the media do; we outline four principal ways of processing messages with subliminal content; we provide the most known evidences of the use of subliminal stimulus in mass media, which caused a big controversy; we analyze experimental studies, which confirm the effectiveness of subliminal stimulation in decision-making and memory improvement; we discuss conditions that must be maintained to achieve effective stimuli.

This research paper provides definitions for the conscious and subconscious minds, and explains their relation with the subliminal messages. We report on and discuss psycholinguistic evidence that shows how the priming technique changes people behaviour just like subliminal messages in the media do. We also provide specific examples of subliminal messages that occurred in the history and what consequences it brought to the media and business

\footnotetext{
${ }^{1}$ The generation born in the late 1990 s or the early 21 st century, perceived as being familiar with the use of digital technology, the internet, and social media from a very young age. (Oxford University Press (OUP), n.d.-b).
} 
industry. Moreover, the main objective of this study is to show whether the subliminal stimuli can affect the learners and if so, how they can motivate them during studying. Therefore, two experiments were carried out which focus on the visual system of subliminal messages in three age groups: children (7 - 12 yrs.), teenagers (13 - 18 yrs.), and adults (18 - 25 yrs.). The children's group showed the greatest improvement, while the teenagers and adults represented a smaller influence of subliminal messages on their memory. The results clarify the potential of subliminal stimuli as a medium for the memory improvement in the first step to the modernized educational system.

\section{THEORETICAL AND CONCEPTUAL FRAMEWORK}

\subsection{Cognitive structures and subliminal messages}

As "The Mind Unleashed" (2013) reveals, the human brain, which is the most complex and sophisticated organ in the human body, is divided into two functional parts with the first one being the conscious mind wherein the brain stores analogical and logical thinking, short term memory, perceptions, critical thinking, thoughts as well as realities detection. However, this part is just the tip of the iceberg as its storage is much smaller than the subconscious mind. The conscious part represents only about $10 \%$ of the brain capacity. On the other hand, the capability of subconsciousness varies between 50-60\% and it includes long term memory, emotions, creativity, beliefs, habits, imagination, intuition, dreams, and values (The Mind Unleashed, 2013).

Most importantly, subliminal messages are commonly confused with the subconscious influence (Kolenda, n.d.) while, in fact, they are different. Subliminal messages operate below the threshold; therefore, the consciousness is not able to detect them even though we are looking hard for any stimulus. The brain is not able to notice them consciously because of their fast or at a low intensity visual or audio display (Sofi \& Nika, 2013, 18).

For an individual, the threshold can vary from day to day or from minute to minute. In addition, thresholds differ rather widely between individuals (Moore, 1982). According to this author, many studies of subliminal perception are flawed, and the reason for this is that investigators assumed that some specific exposure duration or stimulus intensity automatically guaranteed that the stimulus would be sufficiently be low threshold that its presence would be undetected for all the experimental subjects on all the trials.

Often this assumption is unwarranted. Stimuli below the statistical limen (which itself fluctuates) may be noticed as much as $49 \%$ of the time. As a result, studies that make little or no effort to determine a threshold for individual subjects are at risk because stimuli are presented that are effectively supraliminal for some subjects on some trials. The results may thus be due to the effects of weak (but not subliminal) stimulation. (Moore, 1982, p. 39) 
As Karam mentions, our subconsciousness absorbs virtually every kind of information just like "a bed of soil that accepts any kind of seeds, good or bad, with the thoughts that are active, being the seeds" (2017). On the other hand, the subconscious influence called the supraliminal stimuli stands for messages that can be perceived by the brain. Kolenda claims that "a stimulus can influence us subconsciously without being subliminal. If we can see or hear it - even if we don't consciously notice it - it's not subliminal. It's considered supraliminal." It can be visualized with a very interesting experiment made by Hargreaves \& McKenedrick (cited in Kolenda, n.d.) in one liquor store in 1999. When the German music was played in the background, German wine met a bigger interest from the customers' side. However, the reverse happened when French music was played in the store. Doubtlessly, the visitors heard the music, and it eventually affected their subconscious mind. Therefore, we can call it a supraliminal influence.

\subsection{Priming and subliminal messaging}

Apart from subliminal and supraliminal stimuli, there is one term that plays a huge role in the psychology, psycholinguistic, and business worlds, which is priming. As per Elgendi's statement, this specific term refers to "behavior outside of awareness" and also "increased sensitivity to certain stimuli, resulting from prior exposure to related visual or audio messages" (2018). In other words, it stands for the association that is made by neurons in the brain from one word to the next one; for instance, once we see the term "banana", the vast majority of viewers would immediately associate it with the closest interrelation such as "yellow". Subliminal priming (which is very similar to subliminal messages), on the other hand, means the exposure of primed stimulus below the threshold (Elgendi et al, 2018). It is not a cognitive nor conscious perception altered by the brain, but a primed and hidden message appearing as an object of association in the subconscious mind in order to lead the brain to a next thought and, consequently, the following action.

Kolenda mentions some very interesting findings focused on subliminal priming like the one discovered by Fitzsimons et al. in 2008, who claim that the human brain can find more solutions associated with technology to use a brick if the mind is previously primed with the logo of Apple. In consequence, the subliminal priming leads the mind to a certain action, which as an example here is an idea to use the brick as a phone.

\subsection{Types of subliminal stimuli creation}

The subliminal priming and messages, are divided into two main systems, which can transpire as visual and auditory outputs. The system choice always depends on the purpose of stimulus. Furthermore, they are classified as four major types of messages that are excessively used in mass media. All of them contain hidden stimuli that are masked underneath images (visual system) or 
sounds (auditory system) (Karam et al, 2017). However, their display may vary depending on the type of the message:

1. Sub threshold stimuli - impulse flashed in a high speed - undetectable by brain,

2. Masked stimuli - messages masked by other prevailing stimulus such as a preceding flash of light,

3. Unattended stimuli - hiding message that is embedded in other figure, for example, shape of a naked body set in the outlines of ice cubes,

4. Figuratively transformed stimuli - blurred words or images, such as; music lyrics that get a second meaning while they are being played (when they are played) backwards.

All these types appeared throughout history in different fields of mass media, and some of the best examples can be observed in marketing, PR campaign, and music industry.

\subsection{Empirical evidence}

The mentioned types of subliminal stimuli in mass media have been extremely practiced in the whole world, very often becoming in the center of the people's attention, especially when the reveals of subliminal attempts by the largest corporations in the world brought a tremendous controversy. The most common examples are as follows.

\subsubsection{The James Vicary Case}

The first usage of the subliminal stimulus on the audience took place in 1957 as an experiment by James Vicary. These subliminal and supraliminal messages became widely used in various fields of mass media such as marketing, advertising, public relations campaigns, music, films, TV, and politics. The mentioned test of Vicary showcased a huge contribution of subliminal messages to a rapid growth of certain product sales right after their displays in the movie. The content included two messages: "Hungry? Eat popcorn" and "Drink Coca-Cola". As these two stimuli appeared $1 / 3000^{\text {th }}$ of a second every 5 seconds during the display time, the audience was not able to detect them. Furthermore, the subliminal messages aimed directly for the subconsciousness (Sofi \& Nika, 2013). Surprisingly, the final results disclosed that the sales of Coca-Cola increased to $18 \%$, and popcorn sales rose to $58 \%$ after the period of six weeks when the movie "Picnic" with its hidden content was shown to 45,699 viewers (Karam et al, 2017). As a result, the experiment caught a colossal attention of the business world, and regardless the Vicary's revealed in 1962 fraud (BBC, 2015), the biggest companies in the world continued their work on advertising strategies that were escalated with a big obsession to achieve the most satisfying outcomes using subliminal stimuli on mass that is, certainly, not aware of the disguised persuasion. Therefore, the subliminal messages seemed to kingpins of the business world as a perfect tool 
for achieving desired goals on the international stage making their products excessively attractive and increasingly tempting to consumers.

\subsubsection{The use of subliminal message to promote Marlboro}

Marlboro, one of the biggest American companies of cigarettes, was a sponsor of the Ferrari team participating in Formula One. The brand's marketing strategy is a perfect example of figuratively transformed stimuli in history. Since the advertising of tobacco products in the European Union was banned in July 2005, Marlboro came up with a tricky idea to advertise their company by redesigning their logo, which surprisingly, would not resemble their well-known trademark at the first glance, and sticking it on the Ferrari bolide during Formula One race. Just like Alexander Player says, the Marlboro team found a "legal loophole" to advertise their company in Formula One (2016). Intriguingly, once the race began and the prominent design on the bolide got blurred due to fast speed, the logo started working as a subliminal advertising resembling the Marlboro trademark. As a result of the violation of tobacco marketing, Ferrari had to draw it out in 2010 (Elgendi et al, 2018).

\subsubsection{The use of subliminal messages in politics}

Equally confounding, the next example of subliminal stimulus in mass media was used by the Public Relations campaign of George W. Bush with a directed word "RATS" in a television ad right to his Democratic competitor, A1 Gore. The message appears for a very short time in a video when George Bush criticizes his opponent (2018). The controversy was investigated by the Federal Communication Commission (FCC), however, no penalties were implemented.

\subsubsection{The use of subliminal messages in music}

Another very disputable case of subliminal messages saw the light of day in 1985 when two young men committed suicide as a result of listening to British band Judas Priest. The families of teenagers sued the band for placing subliminal information in rock songs "Do it" and "Better By You, Better Than Me" which encouraged two men and contributed to their suicidal attempt. Eventually, the band was exonerated as the judge was not convinced by the families' arguments. Apart from that, there were other cases of suicidal attempts supposedly caused by subliminal messages in rock music. One of these tragedies were mentioned by Al Balad Journal in Lebanon (cited in Karam, 2017) when a young man through himself from a building for Satan. The whole event was watched by the man's friends who confirmed the reason for this suicidal attempt. 


\subsection{Experimental studies}

The phenomenon of influencing the human being's mind through mass media interested many scholars from different countries. In order to find out whether these messages do have an actual impact on the receivers, scientists carried out various experiments.

For instance, a study by Karam et al. demonstrates that subliminal messages can indeed influence our behavior and choices. The main objectives of the researchers' examination are to evaluate the effectiveness of subliminal stimuli and the influence of the auditory system on the people's behavior and more specifically, their choices (2017). As per their two experiments, which involved twenty randomly chosen participants, two CDs with an auditory system of subliminal content were provided to each participant. The recordings contained two messages: the first one was repeating a command "It is OK for me to choose the red color" and the second one contained a number " 128 ". As a result of the first recording, half of the audience selected red among the other two colors, green and blue. However, the researchers consider the possibility of having color preferences, therefore, they assume the results might not show the real influence of the stimuli. Certainly, there is a low probability of having any specific preferences to a three-digit number; consequently, the second experiment was carried out and the outcome turns out to be even more interesting since the $56 \%$ of participants marked number 128 making it the most frequently chosen digit (Karam et al, 2017).

Following the study carried out by Arslan et al., the use of subliminal messages in education met positive feedback from CEIT teachers (407-412), which indicates the faculty is willing to upgrade the current system and is for this kind of modernization. Based on the experiment conducted on CEIT students before mentioned by Arslan et al., we can also understand that youth is ready for new methods in learning.

The next engrossing study that left a big mark on subliminal priming analysis confirms the thesis that subliminal stimuli have an impact on the consumers' behavior. The experiment on youth that was carried out in Kashmir by Sofi and Dr. Nika exposed visual stimuli from TV advertisements to participants in order to evaluate the messages' impact on customers' behavior. The scholars focus here on three categories of ads that are so commonly used by advertisers: pornography and half sexual actions, metaphor, and celebrity endorsement, as these aspects are the most attractive for the audience. The experiment provides the main hypothesis "subliminal messages do tend to create differences in customers behavior" and eleven sub-hypotheses enriching the study with factors that partly affect the consumers' decision making (p. 19). The researchers' focus on the participants' feelings and cognition after watching all three categories of advertising as well as the intensity of impact that leads to compulsive buying. The results demonstrate that once the participants watch specific ads that belong to any of the categories mentioned above, emotions are activated by the brain and became stronger than the cognitive part, thus making the consumers are more likely to buy products 
compulsively. In the end, seven sub-hypotheses out of eleven confirmed the effectiveness of TV ads on a person's behavior.

The vast majority of those studies confirm the effectiveness of subliminal stimulus on the human beings' minds and decision-making. Nonetheless, those scholars did not cover experiments in their analysis specifically related to the possible effects of the messages on learners as a selfhelp, which is crucial in this research topic to investigate.

However, a very compelling study, which was coordinated by Chakalis and Lowe (1992), confirms the positive effects of subliminal stimulation on human memory, which can affect the successful outcomes during learning. This study conducts an experiment involving sixty participants, who were assigned into three groups (one control and two experimental groups). The research aimed to investigate whether the usage of subliminal stimuli in the auditory system is an useful tool for short-term memory improvement. Each of the three groups included twenty volunteers; the first group was not exposed to any sound, the second one was presented to the relaxing melody only, and the third one was displayed to subliminal cassette with memory-improvement affirmation hidden in a relaxing music. The whole experiment included three sets of presenting the eight pictures of the men to make the participants memorize as many details as possible. After each set, the volunteers were asked to recall information about each man from the pictures. After the last presentation of photographs, the participants were requested to answer given questions related to the names and occupancy of each man shown before. As a result, the third group exposed to subliminal stimuli with memory improvement achieved the highest scores in comparison to the other two groups confirming that subliminal messages do improve memory (Chakalis \& Lowe, 1992, pp. 956-958). Furthermore, this positive result can be used by learners for their educational success.

\subsection{Effective stimulation}

As per many experiments, these systems and types of messages can affect, to a certain extent, the human behavior, thinking, memory, and decision making by targeting the subconsciousness. However, as per many scholars, it can be possible only under some conditions:

a. If a message abides by particular guidelines of programming. Whether a stimulus is strong enough that cannot be nullified by other impulses as well as it repeats in a specific frequency for a sufficiently long time (Karam et al. 2017),

b. If the external factors do not interfere the correct reception, for example, relaxing music is highly recommended as a masking tool in the audio system to introduce the listeners to the "alpha brainwave state" (Karam et al. 2017),

If the receivers are already showing a will towards a particular behavior. The Karremans' experiment from 2006 with a subliminal priming of Lipton Ice 
indicates a perfect explanation of a phenomenon when the audience showed preferences towards the primed beverage (Hardin, 2019). Since the participants were already thirsty before the subliminal priming with Lipton Ice, the message influenced them to choose this specific beverage. The study confirms the assumption that the thirsty audience after being subliminally primed preferred the Lipton Ice, among other drinks. Interestingly, the same authors also carried out a second experiment, which indicates that once the audience is not thirsty (does not indicate the will to a certain behavior), the interest in the stimulated (primed) beverage does not take place whatsoever.

\section{METHODOLOGY}

\subsection{The research model}

The experiment consisted of two phases. In the second phase the participants were divided into two groups - experimental and controlled group, unlike the first phase where all participants were in one group. Three videos were prepared for these two steps of the experiment.

The first video was made in the first study phase in order to examine whether the subliminal stimuli affect the subconsciousness and influences the participant's choice of numbers. Therefore, a three-digit number (810) was included in this video to check if the participants from the experiment group could detect it. The video was a trailer of the Netflix movie "Our Planet", which was 1:38 mins long, so the participants would stay focused to watch the whole video watch. After the experiment, the participants from the experiment and control groups were asked to fill out the questionnaire which included a question asking to choose one three-digit number.

Qualitative and quantitative research methods were used for this research study, which corresponded to key questions such as: "why did you choose this number" and "what were you thinking about during watching this video". These semi-structured open questions were prepared and asked for the feedback related to the video from the first phase. In this manner, it was useful to comprehend whether the participants could detect the numbers as flashing images and what they were thinking about during watching the video. It was crucial to examine if the participants paid much attention to the content of the video or flashing images with the numbers take over their attention. 


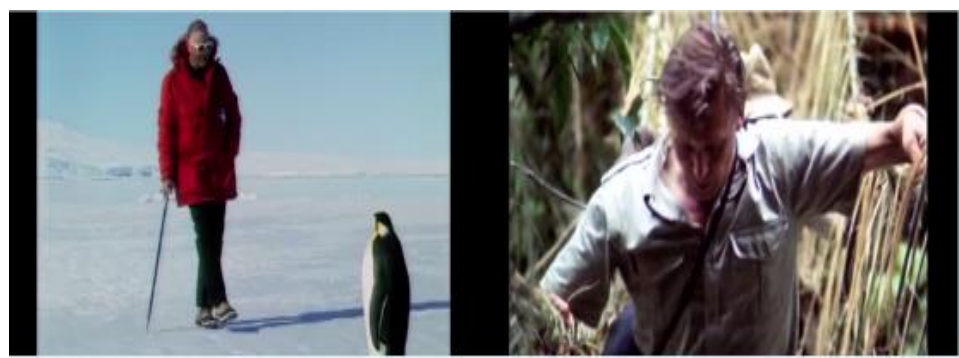

\section{Image 1: Video 1 “Our Planet”}

The second and third videos edition were planned for the second phase of this research, which concentrates on the effectiveness of subliminal stimuli on learners in three age groups and how it can motivate them via strengthening their memorizing skills. The subliminal stimuli (visual) was considering the goal of improving the learning outcomes in each age group; children (7-12 yrs.), teenagers (13-18 yrs.), and adults (18 - 25 yrs.). The research was based on observation, analysis, and evaluation of the experiment on different age stages. In these two videos, a message "remember details" was displayed to the participants from the experimental group in each age section. The message was repeated several times throughout the videos. The control groups watched the same videos without the subliminal stimuli. The first video, "Destiny", was a 1:11 mins long animation.

The second video from the same phase was a movie trailer of Charlie Chaplin documentary (1:6 mins). The videos have interesting content for all ages and are cluttered with various footage that made it much easier to add subliminal stimuli between the cuts and ask various questions about the smallest details.

Semi-structured closed questions were prepared with the aim of finding out the participants' perception related to the details from the last two videos from the second phase of the experiment. The questionnaire contains eight questions related to the details from both films. The messages in all videos from both experiments were flashed below the threshold in the speed of 1/60 frames per second.

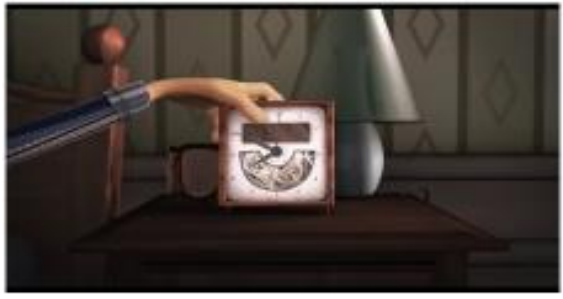

Image 2: Video 2 "Destiny"

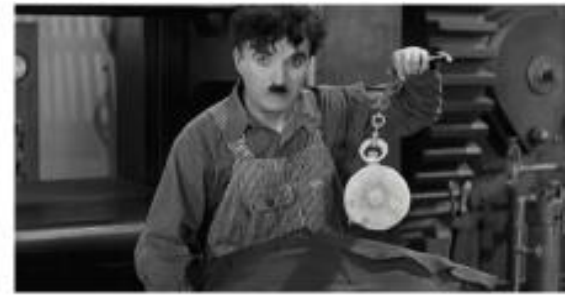

Image 3: Video 3 Charlie Chaplin 


\subsection{Participants}

In the first phase of the study 25 participants were involved, and 45 participants were involved in the second part of the study.

The participants were UAE residents. The participants were split into three groups:

- children between 7 and 12 years old,

- teenagers between 13 and 18 years old,

- $\quad$ adults between 19 and 25 .

Each age group includes an equal number of participants of both sexes in order to avoid biased results. One of the conditions to be a participant in the study was to speak English fluently. Therefore, their subconsciousness could comprehend the subliminal stimuli in the second and third videos. The aim was to observe how each age group perceives the messages and how it affects their choices of numbers as well as memorizing skills.

\subsection{Data collection tools}

The study was anonymous and voluntary. All groups participated in the study online via Google Forms. The participants from the youngest groups were approached through their guardians or parents who were informed about the purpose of the study and could decide whether they want their child to take part or not.

The observations for both study phases were recorded on Google Forms throughout a week. All data were downloaded and summarized in an excel document focusing on the percentage of correct answers from the second phase of the study.

The results of the first phase were analyzed qualitatively and quantitatively in order to examine whether the stimulus was properly prepared for the same technique to be used for the second part of the study. The second phase was analyzed quantitatively since the focus point was only the percentage of the correct answers.

\section{RESULTS}

During the first phase of the experimental study, among the 25 participants, $64 \%$ of them were able to identify the three-digit code flashed in the first video correctly. When the same respondents were asked if they had noticed any flashing image while watching the video, $60 \%$ responded positively while $32 \%$ saw an image, but it wasn't clear what they saw precisely. The rest, $8 \%$, did not notice anything. 


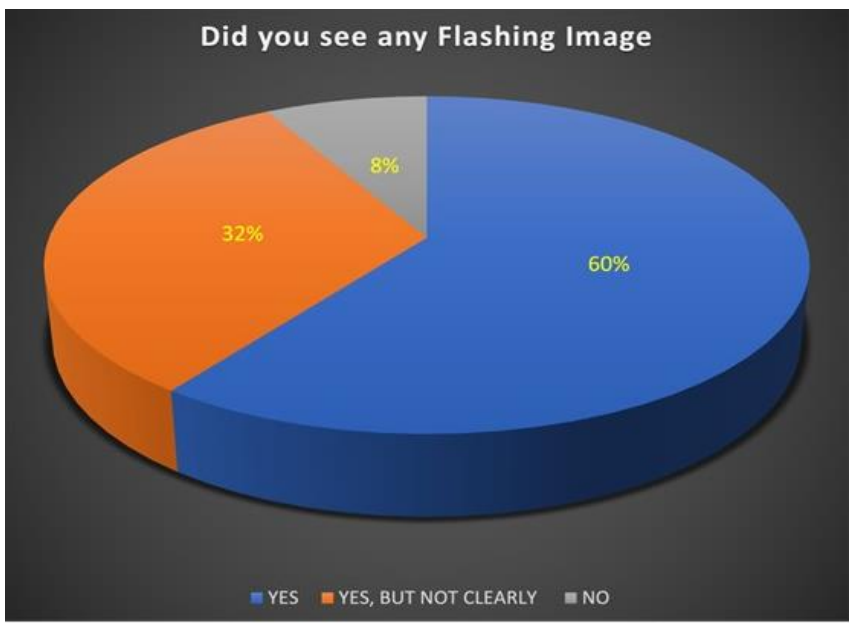

Figure 1: Phase I - Did you see any Flashing Image?

Further the participants were asked what they were thinking about while watching the video "Our Planet". The responses were associated with nature, the planet, global warming, animals, and environment. There were no responses which were related to the flashing images shown during the video nor the numbers, which would signal that the participants were distracted by them.

In the second phase, the experimental groups from all age sections influenced by subliminal stimuli got $83 \%$ correct answers. In comparison, the control group with no exposure to subliminal stimuli got $73 \%$ of the correct answers. The experimental and control groups were divided into three subcategories: children between 7 and 12 years old, teenagers between 13 and 18 , and adults between 19 and 25 .

The control group of children got $66 \%$ correct answers, and the experimental group of children exposed to subliminal messages got $82 \%$ correct answers, which is a massive increase of $16 \%$.

Teenagers had a minor increase of $10 \%$; the control group reached $76 \%$ correct answers, while the experimental group achieved $86 \%$.

Adults showed the least growth of only $6 \%$, i.e., the control group got $75 \%$, and the experimental group reached $81 \%$. 


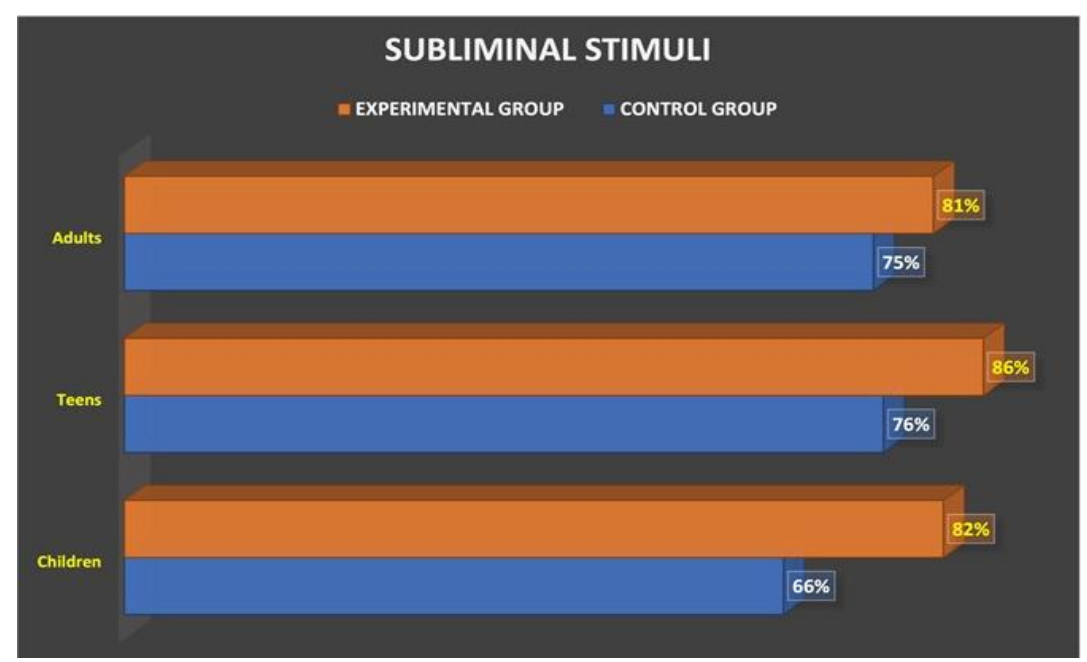

\section{Figure 2: Subliminal Stimuli across age groups}

The results prove that subliminal stimuli can affect and influence people to improve their learning process and help them with renewed focus. In turn, it can enhance the effectiveness of teaching.

The stimuli are more effective for the younger generation. It is clear that as someone is older is harder to be under the influence of the subliminal stimuli. This also points towards ways and means of increasing the effectiveness of the stimuli on teenagers and adults. One way would be to increase the exposure of the stimuli on the subject.

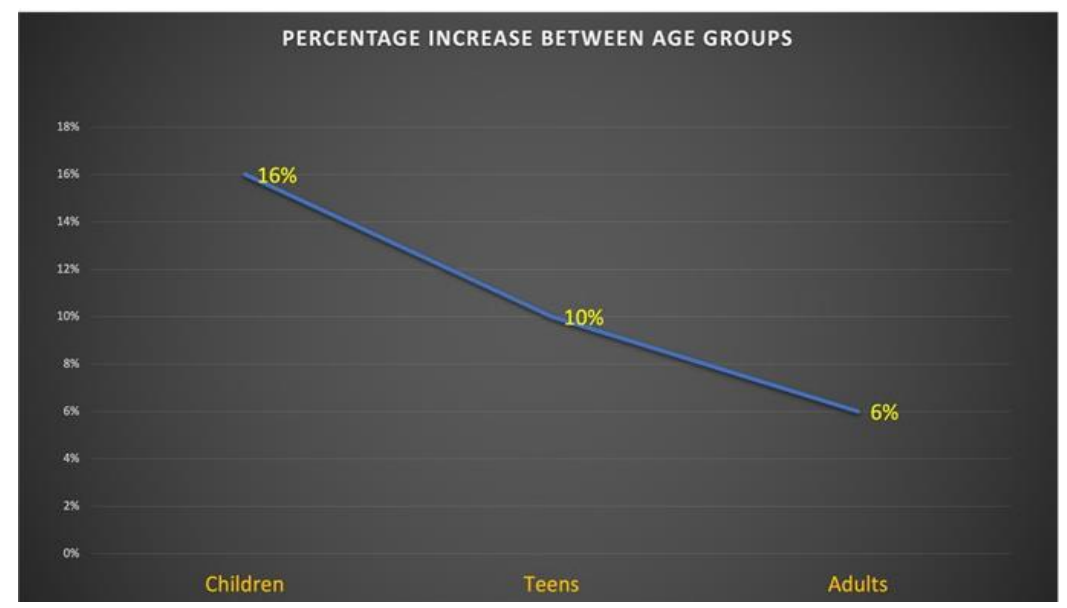

Figure 3: Percentage increase between control and experimental group

In continuation of the study in the future, appropriate steps would be considered to find the right amount and intensity of subliminal message on a particular audience, including teenagers and adults. 


\section{CONCLUSION AND DISCUSSION}

The effectiveness of subliminal stimulation can be a powerful tool for many platforms. Therefore, the biggest companies in the world spend millions of dollars to see the difference in their sales before and after implementing subliminal stimuli. We can see the evidence in advertising, music, politics, and even in the self-development industry with self-help tapes. That is why priming and subliminal messages in mass media have been widely practiced as their prosperous results reach the biggest companies' expectations to attract and, at a certain level, influence their receivers eventually.

The experiment from both the phases in this study confirm the influence of the visual technique on people's subconsciousness (to a bigger or smaller extent). Certainly, the largest corporations in the world have been immensely attached to priming and subliminal messages for over fifty years, and they will definitely keep on using this tactic without missing a beat as their efficiency is doubtlessly promising.

However, the tremendous controversy regarding the commercial purposes of subliminal stimuli can be cooled down since the efficacy depends on many crucial factors such as; environmental variables, the length of priming, frequency, and reiteration of subliminal stimulus, as well as the audience mental resistance and age. Subliminal messages require a specific process of creation in order to accomplish work with positive outcomes. The key influencers of the world who are regarded as thought leaders of the generation can use subliminal messages to influence their followers. The efficiency tilts towards the younger generation, and herein lies the dangers of early mind conditioning. Subliminal messages on social media can hurt impressionable young children, and this experiment can be tuned to meet the challenges created by social media platforms.

Nevertheless, it can be a promising tool to help students reach their goals in education. This study focuses on the effectiveness of subliminal messages and how they can help learners. As the way of approaching the subconscious mind can be possible through two main subliminal stimuli: video and auditory systems, we decided to conduct a study based on a visual stimulus.

In this paper, it can be observed that the visual and mind interrelationship can have an effective impact on a person's behavior and choice-making. Moreover, the subliminal video content can be used for various purposes, especially as a self-help tool like learners' motivation and the memory improvement. The difficulties with learning affect students' education and create big obstacles to achieve higher grades and, more importantly, students' self-development. That is why this study was conducted and it indicates that helping learners through subliminal stimuli is possible on many stages. In this case, a message "Remember Details" showed to be a promising tool. Educational institutions can adopt the results from the study in creating learning materials that increase the effectiveness of their intervention measures at various levels of the education system. Institutions of higher education have primarily adopted audio and video materials to supplement the course 
materials. The results of the study are encouraging enough to add specific measures to this end.

Furthermore, as per the quantitative experiment in the second phase of this study, the use of subliminal messages indicated to be more effective on young minds, especially in the group of children between 7 and 12 years old. While the group of teenagers, which were exposed to the same amount and frequency of stimuli, represents a smaller change. The adults' section turned out to be the least vulnerable, which requires more research on a specific amount and saturation of subliminal stimuli as video content.

\subsection{Future works}

As it is commonly known, students at school and universities are often late for their classes, do not read books and, even more frighteningly, do not buy them, so in the future works the stimuli would need to include certain information to improve the mentioned above behavior. Examples of phrases used to support the learning outcomes can include: "Don't be late to your class", "I love reading books", "I study hard", and "I take notes in classes". There are plenty of propositions to achieve the most successful content and to reach such results as, memory improvement, better attendance, arrival to classes on time, growth of participation, purchase of books, note-taking, books reading, public speaking as well as higher self-esteem. The messages can be in the form of advertising displayed at schools and universities and also as the self-help videos made to watch during breaks just like in the experiments carried out in this study. The messaging can be made part of a concerted campaign at the beginning of a term to bring faith to the universities outreach effort towards the new graduates joining rank at the university. Future research projects should explore studies focused on the education and effectiveness of such a powerful tool. 


\section{References}

Arslan, H., Ozdemir, M., \& Kuscu, M. (2017). Teachers' perception related to the usability of subliminal message techniques in education. European Scientific Journal, ESJ, 13(7), 81.https://doi.org/10.19044/esj.2017.v13n7p81

Does subliminal advertising actually work? (2015, January 20). BBC News. Retrieved from https://www.bbc.com/news/magazine-30878843

Elgendi, M. et al. (2018, May 30). Subliminal priming - state of the art and future perspectives [Electronic version]. Retrieved from https://www.ncbi.nlm.nih.gov/pmc/articles/PMC6027235/

Hardin, E. (2019, March 29). Myth: subliminal messages can change your behavior. Association for Psychological Science. Retrieved from https://www.psychologicalscience.org/uncategorized/myth-you-canbe-influenced-by-things-outside-your-awareness.html

Karam, R. et al. (2017, June). Effectiveness of subliminal messages and their influence on people's choices [Electronic version]. European Scientific Journal. 13(17), 262-276. Retrieved from http://eujournal.org/index.php/esj/article/view/9524/9032

Kolenda, N. (n.d). Do Subliminal Messages Really Work? Retrieved from https://www.nickkolenda.com/subliminal-messages/

Lakhani, D. (2008). Subliminal Persuasion Influence \& Marketing Secrets They Don't Want You to Know. John Wiley \& Sons, Inc. New Jersey

Moore, T. E. (1982). Subliminal advertising: What you see is what you get. Journal of Marketing, 46(2), 38-47. https://doi.org/10.2307/3203339 Retrieved from https://www.researchgate.net/publication/235361056_Subliminal_Ad vertising_What_You_See_Is_What_You_Get

Oxford University Press (OUP). (n.d.-b). Generation Z. Lexico.Com. https://www.lexico.com/definition/generation_z

Sandoval, A. V., Torres, J. S., Castillo, L. C. Z. (2018). Subliminal Messages and Their Impact on Young People's Consumption Beliefs and Attitudes. Revista Universitaria Ruta Vol. 20 II. Retrieved from https://www.researchgate.net/publication/331562257_SUBLIMINAL _MESSAGES_AND_THEIR_IMPACT_ON_YOUNG_PEOPLE\% 2 7S_CONSUMPTION_BELIEFS_AND_ATTITUDES

Sofi, S. A. \& Nika, F. A. (2013, December). Impact of subliminal messages in TV advertisements on customer behavior (a case study on youth in Kashmir province of J\&K). Journal of Business Management \& Social Sciences Research. 2(12), 17-27.

Subliminal Definition \& Meaning | Dictionary.com Retrieved from: https://www.dictionary.com/browse/subliminal

Subliminal adjective - Definition, pictures, pronunciation and usage notes | Oxford Advanced Learner's Dictionary at OxfordLearnersDictionaries.com from: 
https://www.oxfordlearnersdictionaries.com/definition/english/sublim inal

Subliminal | meaning in the Cambridge English Dictionary. Retrieved from:

https://dictionary.cambridge.org/dictionary/english/subliminal

Sur, R. (2015). Impact of Subliminal Messages on Consumer Behavior: A Fresh Look into the Future. Retrieved from https://papers.ssrn.com/sol3/papers.cfm?abstract_id=2638633

Kouider, S. \& Faivre, N. (2017). Conscious and Unconscious Perception. The Blackwell Companion to Consciousness, Second Edition. Edited by Susan Schneider and Max Velmans. (pp. 551 - 561). John Wiley \& Sons Ltd.

The Mind Unleashed (2014, November 6). The conscious, subconscious, and unconscious mind - how does it all work? Retrieved from https://themindunleashed.com/2014/03/conscious-subconsciousunconscious-mind-work.html 